\title{
Cost-Utility of Using Alzheimer's Disease Biomarkers in Cerebrospinal Fluid to Predict Progression from Mild Cognitive Impairment to Dementia
}

Citation for published version (APA):

Handels, R. L. H., Wimo, A., Dodel, R., Kramberger, M. G., Visser, P. J., Luis Molinuevo, J., Verhey, F. R. J., \& Winblad, B. (2017). Cost-Utility of Using Alzheimer's Disease Biomarkers in Cerebrospinal Fluid to Predict Progression from Mild Cognitive Impairment to Dementia. Journal of Alzheimer's Disease, 60(4), 1477-1487. https://doi.org/10.3233/JAD-170324

Document status and date:

Published: 07/11/2017

DOI:

10.3233/JAD-170324

Document Version:

Publisher's PDF, also known as Version of record

Document license:

Taverne

Please check the document version of this publication:

- A submitted manuscript is the version of the article upon submission and before peer-review. There can be important differences between the submitted version and the official published version of record.

People interested in the research are advised to contact the author for the final version of the publication, or visit the DOI to the publisher's website.

- The final author version and the galley proof are versions of the publication after peer review.

- The final published version features the final layout of the paper including the volume, issue and page numbers.

Link to publication

\footnotetext{
General rights rights.

- You may freely distribute the URL identifying the publication in the public portal. please follow below link for the End User Agreement:

www.umlib.nl/taverne-license

Take down policy

If you believe that this document breaches copyright please contact us at:

repository@maastrichtuniversity.nl

providing details and we will investigate your claim.
}

Copyright and moral rights for the publications made accessible in the public portal are retained by the authors and/or other copyright owners and it is a condition of accessing publications that users recognise and abide by the legal requirements associated with these

- Users may download and print one copy of any publication from the public portal for the purpose of private study or research.

- You may not further distribute the material or use it for any profit-making activity or commercial gain

If the publication is distributed under the terms of Article 25fa of the Dutch Copyright Act, indicated by the "Taverne" license above, 


\title{
Cost-Utility of Using Alzheimer's Disease Biomarkers in Cerebrospinal Fluid to Predict Progression from Mild Cognitive Impairment to Dementia
}

\author{
Ron L.H. Handels ${ }^{\mathrm{a}, \mathrm{b}, *}$, Anders Wimo ${ }^{\mathrm{b}}$, Richard Dodel ${ }^{\mathrm{c}}$, Milica G. Kramberger ${ }^{\mathrm{b}, \mathrm{d}}$, \\ Pieter Jelle Visser ${ }^{\mathrm{a}, \mathrm{e}}$, José Luis Molinuevo ${ }^{\mathrm{f}, \mathrm{g}}$, Frans R.J. Verhey ${ }^{\mathrm{a}}$ and Bengt Winblad $^{\mathrm{b}}$ \\ ${ }^{a}$ Department of Psychiatry and Neuropsychology, Alzheimer Centre Limburg, School for Mental Health and \\ Neurosciences, Maastricht University, Maastricht, The Netherlands \\ ${ }^{\mathrm{b}}$ Department of Neurobiology, Care Science and Society, Center for Alzheimer Research, Division \\ of Neurogeriatrics, Karolinska Institute, Huddinge, Sweden \\ ${ }^{\mathrm{c} D e p a r t m e n t ~ o f ~ N e u r o G e r i a t r i c s, ~ U n i v e r s i t y ~ D u i s b u r g-E s s e n, ~ E s s e n, ~ G e r m a n y ~}$ \\ ${ }^{\mathrm{d}}$ Department of Neurology, University Medical Center Ljubljana, Ljubljana, Slovenia \\ ${ }^{\mathrm{e}}$ Department of Neurology and Alzheimer Centre, VU University Medical Centre, Amsterdam, The Netherlands \\ ${ }^{\mathrm{f}}$ Alzheimer Disease and Other Cognitive Unit, Hospital Clinic, IDIBAPS, Barcelona, Spain

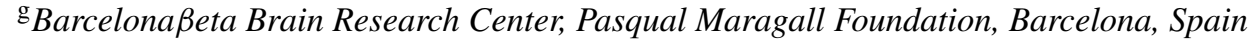

Handling Associate Editor: Sophie Vandepitte

Accepted 17 August 2017

\begin{abstract}
.
Background: Diagnostic research criteria for Alzheimer's disease support the use of biomarkers in the cerebrospinal fluid (CSF) to improve the accuracy of the prognosis regarding progression to dementia for people with mild cognitive impairment (MCI).

Objective: The aim of this study was to estimate the potential incremental cost-effectiveness ratio of adding CSF biomarker testing to the standard diagnostic workup to determine the prognosis for patients with MCI.

Methods: In an early technology assessment, a mathematical simulation model was built, using available evidence on added prognostic value as well as expert opinion to estimate the incremental costs and quality-adjusted life years (QALYs) of 20,000 virtual MCI patients with (intervention strategy) and without (control strategy) relying on CSF, from a health-care sector perspective and with a 5-year time horizon.

Results: Adding the CSF test improved the accuracy of prognosis by 11\%. This resulted in an average QALY gain of 0.046 and $€ 432$ additional costs per patient, representing an incremental cost-effectiveness ratio of $€ 9,416$.

Conclusion: The results show the potential of CSF biomarkers in current practice from a health-economics perspective. This result was, however, marked by a high degree of uncertainty, and empirical research is required into the impact of a prognosis on worrying, false-positive/negative prognosis, and stigmatization.
\end{abstract}

Keywords: Alzheimer's disease, cerebrospinal fluid, cost-utility, economic evaluation, mild cognitive impairment, prognosis, risk

\footnotetext{
*Correspondence to: Ron Handels, Alzheimer Centre Limburg, Maastricht University, P.O. Box 616, 6200 MD Maastricht,
} 


\section{INTRODUCTION}

With a global prevalence of 47 million [1] and a corresponding economic impact of US\$ 818 billion [2], dementia imposes a substantial burden on societies worldwide. Limited national care budgets force governments and health insurers to reimburse only a selection of all available healthcare technologies. These choices are ideally based on cost-effectiveness evidence, such that the available budget is spent on the selection of interventions that result in the maximum societal health gain.

Clinical guidelines for suspected Alzheimer's disease (AD) recommend a standard assessment of clinical history, cognition, behavioral symptoms, co-morbidities, and neuroimaging in patients with suspected dementia [3]. In the last decade, proposals for new research-based diagnostic criteria for AD have been developed, including advanced diagnostic technologies that enable the early identification of brain abnormalities [4-7]. As regards CSF biomarkers, the evidence base for these recommendations is formed by studies of diagnostic and prognostic accuracy [8].

Diagnostic tests are, however, no exception to any other health intervention $[9,10]$; because they consume part of the health care budget means that this part cannot be spent on an alternative intervention and its corresponding opportunity to gain health. To support reimbursement by governments or health insurers, diagnostic tests should therefore be evaluated in terms of incremental cost-effectiveness using clinical or quality-adjusted life year (QALY) outcomes. This allows intervention effects to be compared between different diseases, as reflected by different outcomes, to enable a well-informed decision to be made about reimbursement.

A few studies have attempted to reflect the clinical utility of CSF biomarkers by assessing the impact on diagnostic decision making $[11,12]$ or diagnostic confidence [13] of adding CSF biomarkers to standard clinical tests. The results were mixed, and the studies did not report on health effects. A systematic review on the effect of early identification of AD hallmarks did not find any empirical evidence of health benefits derived from persons with and without identified AD-related brain abnormalities in pre-dementia [14]. Nevertheless, this and other reviews reported on the potential benefits and harms of early [14] and genetic testing [15] or a timely diagnosis [15] of $\mathrm{AD}$ or other neurodegenerative disorders [16]. This includes benefits related to decreased anxiety if the cause is found not to be $\mathrm{AD}$, management of cognitive symptoms to reduce the related burden, and planning for future care and personal adjustments to prevent burden or crisis situations when symptoms increase. Potential harms include the impact of stigmatization, anxiety and depression after a diagnosis is communicated (whether true or false), and the side-effects of the lumbar puncture, such as headache. In the absence of a registered treatment, no benefits can be expected in terms of slowing down the disease progression in the pre-dementia stage of $\mathrm{AD}$.

Previous studies on the cost-effectiveness of using CSF markers have either disregarded any potential health impact [17] or assumed a hypothetical diseasemodifying treatment [18-22] to be decided upon based on CSF test results. Such results only reflect a limited part of the potential impact of CSF testing.

The lack of empirical evidence on health effects related to CSF testing limits the appraisal of this technology to support reimbursement decisions. Further advancement of the health-economic assessment of CSF requires identifying the topics for future empirical research. This could be done in an early technology assessment [23], which could identify drivers of uncertainty as well as assess the sensitivity of health-economic outcomes to different sets of assumptions on parameters for which evidence is lacking. Such early assessment could also determine the potential of CSF tests, which, if it proves to be substantial, would argue for supporting further empirical research into input parameters for which little evidence is available. Finally, it could aid in the development of a simulation framework that reflects clinical practice and aggregates the pieces of evidence from various sources. The aim of this study was to estimate the potential incremental cost-effectiveness ratio of adding CSF biomarker testing to the standard diagnostic workup to determine the prognosis for patients with MCI. An early technology assessment was performed by means of a simulation study using existing evidence as well as plausible assumptions on potential health benefits and harms, without evaluating any hypothetical treatment.

\section{MATERIALS AND METHODS}

The potential cost-effectiveness of CSF was estimated using a decision model that simulates the diagnostic test workup in usual care to establish a prognosis for progression to dementia (by means of predictive values using a logistic regression model) 
and comparing this with a simulation of a situation in which CSF biomarkers are added to the usualcare diagnostic test workup to establish a prognosis for progression to dementia (using the same logistic regression model but with CSF biomarkers added). This was done for a group of virtual patients who visit a memory clinic for the first time and have been diagnosed with MCI. The model estimates the incremental costs and effects for a strategy in which the prognosis is based on the diagnostic workup recommended for usual care and a strategy in which the prognosis is based on adding a CSF test to the diagnostic workup recommended for usual care. No treatment effects were reflected in the model because currently none are recommended for MCI. The Supplementary Material describes in detail the model structure, data analysis, consistency, and results. The model code is available on http://www.smard.org or upon request to the corresponding author.

In the domain of public health, a progression to any-type dementia can be considered more important than identifying the cause of this progression as being $\mathrm{AD}$, vascular disease, or other. Hence, we focused on the prognosis for progression to any-type dementia rather than the diagnosis of its sub-types. Nevertheless, since the underlying cause is required to determine the prognosis, this study partly represents the value of using CSF biomarkers for diagnosing the underlying pathology.

\section{Model structure}

The simulation started by creating a virtual group of individual MCI patients and their characteristics of age, gender, level of education, underlying neurodegenerative disease (present or absent), CSF biomarker values (amyloid- $\beta 1-42$, total tau, and phosphorylated tau), cognition, memory, and medial temporal atrophy on MRI. For each patient, the following events were simulated: 1) a prognosis consisting of a probability of developing any-type dementia; 2) one or more follow-up visits to a memory clinic for a clinical evaluation; 3 ) progression to dementia; and 4) death. Simulated effects also included the impact of the prognosis in terms of reduced worrying and stigmatization, the impact of a false-positive/negative prognosis, and the impact of lumbar puncture side-effects on health-related quality of life (HrQOL). Simulated costs included the visits to the clinic, lumbar puncture, and costs related to MCI and dementia. See Fig. 1 for a simple overview of the model structure.
The model was based on various assumptions, such as: 1) a patient with no neurodegenerative disease will never develop dementia; 2) a patient with a neurodegenerative disease will develop dementia within the model's time frame of 5 years; 3 ) dementia is irreversible; and 4) the probability of dementia progression corresponds to the dementia prognosis and degree of certainty communicated to a patient. A full list of assumptions can be found in the Supplementary Material 2.4 .

\section{Control and intervention strategy}

The model simulated a control strategy, which reflected the effects of a prognosis of progression to dementia over a 5-year period using the standard test workup [3], and an intervention strategy, in which CSF biomarker results are added to this workup. The prognosis was established using a prediction model [24] based on demographic information and results from tests on cognition, depression, and neuroimaging, and a prediction model adding CSF test outcomes to the first prediction model.

\section{Preparatory data analyses}

Both the characteristics of the virtual patients at their initial visit and their risk of progression to dementia were simulated using the results of a study by Handels et al. [24] based on set of merged data from different cohort studies.

The decision model simulated 20,000 virtual patients and their characteristics using random draws from the study participants' distribution and correlation structure. Table 1 represents the characteristics of the merged dataset and of the characteristics of the simulated virtual patients based on the averages and distributions of the patients in the merged dataset.

Each virtual patient's prognosis was simulated by applying a dementia progression prediction model [24] to the characteristics of the 20,000 simulated patients. A prognosis was a predicted probability of progression to dementia. Two prognoses were simulated: one representing the control strategy (using all test information except CSF biomarkers) and one representing the intervention strategy (using all test information including CSF biomarkers).

Regular follow-up visits were simulated if the prognosis (i.e., predicted probability of progression to dementia) was positive (i.e., a predicted probability $\geq 0.50$ ) or uncertain. Clinical experts considered a prognosis uncertain if the probability was higher 


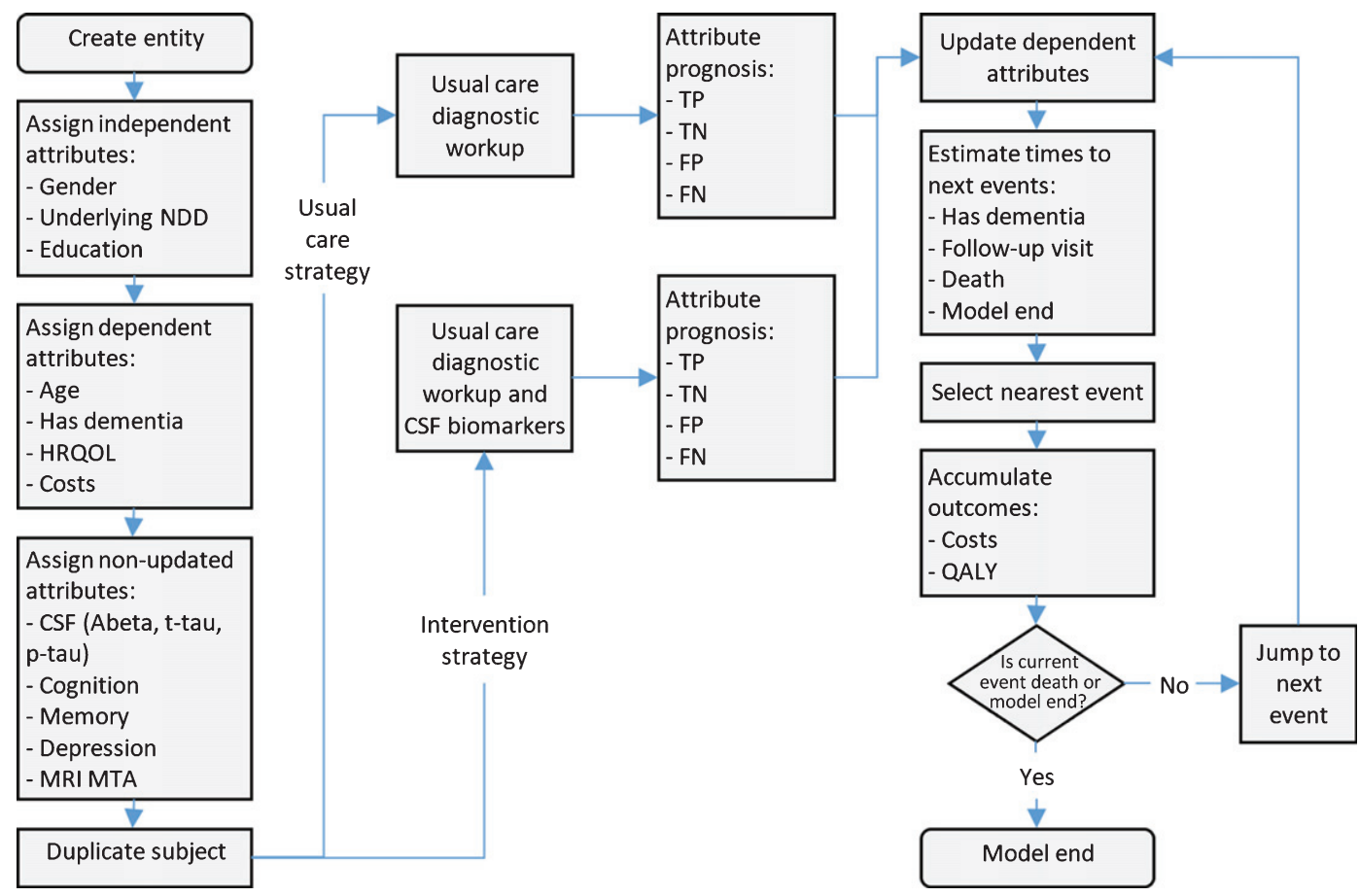

Fig. 1. Basic model structure (abbreviations: CSF, cerebrospinal fluid; FN, false-negative prognosis; FP, false-positive prognosis; HrQOL, health-related quality of life; MRI MTA, medial temporal lobe atrophy on magnetic resonance imaging; NDD, neurodegenerative disorder; TN, true-negative prognosis; TP, true-positive prognosis; QALY, quality-adjusted life year).

Table 1

The observed baseline characteristics of 250 participants in the cohort studies analyzed by Handels et al. [24] and the simulated baseline characteristics of the 20,000 patients entering the decision model

\begin{tabular}{lccccc}
\hline Characteristic & \multicolumn{2}{c}{ Original study } & & \multicolumn{2}{c}{ Simulated cohort } \\
\cline { 2 - 3 } \cline { 5 - 5 } & $68.6(7.5)$ & 52.0 to 89.0 & & $68.7(8.1)$ & 35.2 to 101.8 \\
Age & $111(44 \%)$ & NA & & $45 \%$ & NA \\
Female gender & $11.2(3.1)$ & 4 to 18 & & $11.2(3.2)$ & -2 to 24 \\
Education, $y$ & $26.9(2.4)$ & 18 to 30 & & $27.0(2.4)$ & 12 to 30 \\
MMSE & $-1.6(1.2)$ & -5.6 to 2.3 & & $-1.6(1.2)$ & -6.2 to 3.7 \\
WLT delayed recall z-score & $0.3(0.6)$ & 0 to 2 & & $0.3(0.5)$ & 0 to 4 \\
Depression 1 & $2.3(1.8)$ & 0 to 6 & & $2.2(1.7)$ & 0 to 6 \\
MRI MTA left and right & $666(296)$ & 157 to 1538 & $661(268)$ & 37 to 1666 \\
CSF A $\beta$ & $446(237)$ & 52 to 1179 & & $457(262)$ & 0 to 1396 \\
CSF t-tau & $71(30)$ & 16 to 172 & & $69(14)$ & 25 to 133 \\
CSF p-tau & $99(40 \%)$ & NA & & $25 \%$ & NA \\
Progression to dementia (events) & & &
\end{tabular}

Table partly copied from Handels et al. [24] with permission of the author. ${ }^{1} 0=$ no symptoms, $1=$ mild symptoms, 2 = moderate symptoms. CSF, cerebrospinal fluid; MMSE, Mini-Mental State Examination; MRI, magnetic resonance imaging; MTA, medial temporal lobe atrophy; WLT, word learning test; SD, standard deviation.

than 0.24 , and on average recommended to follow up patients every 9.3 months for a maximum of 5 years. Patients with a low probability of decline $(<0.24)$ were sent home. If the test result was false-negative, they returned to the clinic 1 year after progression to dementia occurred.

The following aspects were assumed to influence the HrQOL of each simulated patient: MCI syndrome, worrying about progression to dementia, false-positive prognosis, false-negative prognosis, stigmatization, and lumbar puncture adverse effects. These effects were expressed in terms of a utility, a number ranging from 0 (reflecting the worst possible health state or death) to 1 (reflecting a perfect health state). Each simulated patient was assumed to worry about their possible progression to dementia before having visited a medical professional. The clinical experts in our study estimated that worrying 

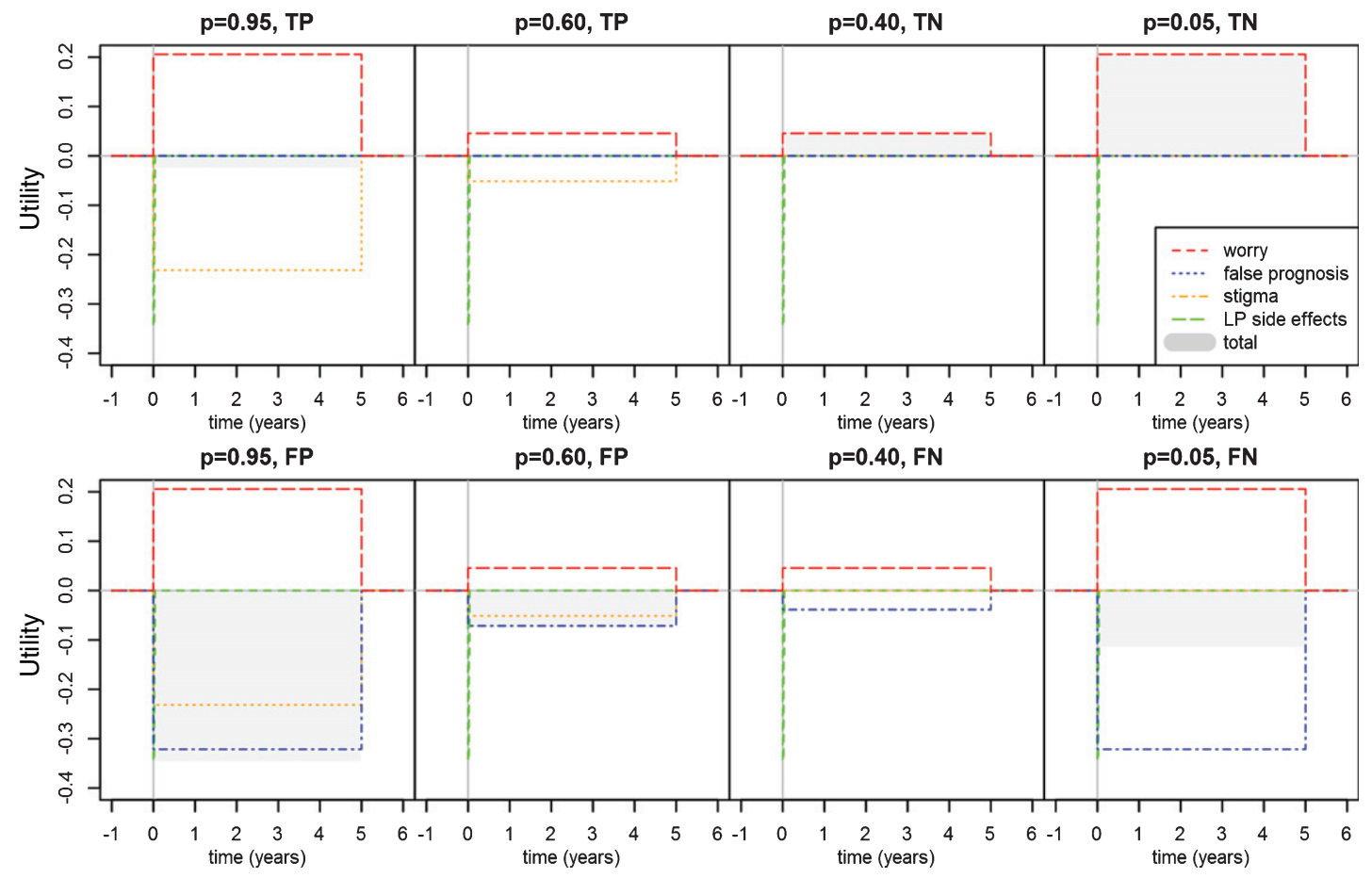

Fig. 2. Overview of the assumed impact of reduced worrying, false-positive/negative prognosis, stigma and lumbar puncture side-effects on a patient's utility. FN, false-negative prognosis; FP, false-positive prognosis; TN, true-negative prognosis; TP, true-positive prognosis; LP, lumbar puncture.

represents a utility decrease of 0.23 . This effect was assumed to reflect maximum uncertainty at a prognostic dementia probability of 0.50 . After testing, a specific prognosis was established for the patient. This prognosis was assumed to correspond linearly to a decreased disutility relating to worrying about dementia. For example, a prognosis of 0.95 reflects a high certainty of progression to dementia, resulting in a reduction of worrying about progression to dementia and thus an increase in utility (see left top Fig. 2, red dashed).

However, this positive prognosis also corresponds to a stigmatizing effect of being labelled as high probability of progression to dementia, resulting in a decrease of utility. The clinical experts estimated this as a 0.26 utility decrease, and it was assumed to correspond linearly to the prognostic dementia probability $(0.26$ at a probability of 1 or when diagnosed with dementia, and 0 at a probability of 0.50 ; see Fig. 2, yellow dashed). The clinical experts estimated the utility decrease due to a false-positive prognosis (probability of progression to dementia between 0.50 and 1 whereas progression to dementia does actually not takes place within 5 years) and a false-negative prognosis (probability of progression to dementia between 0 and 0.50 whereas progression to dementia actually takes place within 5 years) at 0.36 and 0.19 , respectively. These effects were also assumed to correspond linearly to the probability (see Fig. 2, blue dashed). The clinical experts estimated various impacts of side-effects of a lumbar puncture. These were combined with evidence on the probability of occurrence and duration [25] (see Table 2). Details on the method of obtaining expert opinion are included in the Supplementary Material (§3.2.12). Utility scores were linearly interpolated between events to estimate QALYs.

Costs related to MCI and dementia as well as for a clinical visit and the lumbar puncture were obtained from various Swedish sources [26, 27] (see Table 2), reflecting a health-care sector perspective. Prices were converted to Euro 2015 estimates.

\section{Outcomes}

The primary outcome was the average incremental net monetary benefit of the intervention strategy over a period of 5 years. This net monetary benefit was calculated by valuing 1 QALY at $€ 20,000$ [28] and subtracting the costs from it. A positive incremental 
Table 2

Model input parameters (2015 price estimates)

\begin{tabular}{|c|c|c|}
\hline Category & Parameter & Parameter estimate for individual \\
\hline \multirow[t]{2}{*}{ Patient characteristics } & $\begin{array}{l}\text { age, gender, education, MMSE, word } \\
\text { learning test, depression, MRI MTA, A } \beta \text {, } \\
\text { t-tau, p-tau }\end{array}$ & See Supplementary Material $\S 3.2 .1$ \\
\hline & Prognostic probability & logistic regression prediction model \\
\hline \multirow[t]{4}{*}{$L P$ related } & Headache & $\begin{array}{l}\text { Bootstrap sampling: none: } p=0.91 \text {; mild } \\
\quad p=0.06 \text {; moderate: } p=0.03\end{array}$ \\
\hline & Headache duration (in days) & $\begin{array}{l}\text { Bootstrap sampling: } 0.5(p=0.26) ; 1.5 \\
\quad(p=0.24) ; 3(p=0.28) ; 7(p=0.22)\end{array}$ \\
\hline & Serious complication & $p=0.01$ \\
\hline & Serious complication duration (years) & $1.1 / 52$ \\
\hline \multirow[t]{2}{*}{ Decisions } & Cut-off probability uncertain prognoses & 0.24 \\
\hline & Follow-up duration (years) & 5 \\
\hline \multirow[t]{5}{*}{ Time to event (years) } & Regular follow-up visit & $9.3 / 12$ \\
\hline & $\begin{array}{l}\text { Patient with underdiagnosed NDD revisits } \\
\text { the clinic }\end{array}$ & 1.0 \\
\hline & Re-establish prognosis & 5 \\
\hline & Progression to dementia & Beta distribution: $\alpha=1.09 ; \beta=2.19$ \\
\hline & Death & Sampling from survival table \\
\hline \multirow[t]{9}{*}{ HrQOL utilities } & MCI & 0.72 \\
\hline & Dementia & 0.63 \\
\hline & Worrying & -0.23 \\
\hline & Stigma of NDD & -0.26 \\
\hline & Impact of FP & -0.36 \\
\hline & Impact of FN & -0.19 \\
\hline & LP mild headache & -0.10 \\
\hline & LP moderate headache & -0.16 \\
\hline & LP serious complication & -0.22 \\
\hline & Base visit & 1210 \\
\hline \multirow[t]{4}{*}{$(€, 2015)$} & Regular follow-up visit & 787 \\
\hline & Lumbar puncture & 621 \\
\hline & Annual care MCI & 3524 \\
\hline & Annual care mild dementia & 10219 \\
\hline
\end{tabular}

CBS, Statistics Netherlands; EP, expert opinion; FN, false-negative prognosis; FP, false-positive prognosis; HrQOL, healthrelated quality of life; $\mathrm{k}$, shape parameter; LP, lumbar puncture; MCI, mild cognitive impairment; MMSE, Mini-Mental State Examination; MRI, magnetic resonance imaging; MTA, medial temporal atrophy; NDD, neurodegenerative disorder; NM, not modelled; p, probability; pc, percentile; p-tau, phosphorylated tau; SE, standard error; t-tau, total tau; $\alpha$, shape parameter; $\beta$, shape parameter; $\theta$, scale parameter.

net monetary benefit reflects the preferred situation of a health gain in terms of QALY improvement at reasonable costs or cost savings (or cost savings at a reasonable QALY loss). Secondary outcomes were total incremental costs, incremental QALYs (1 QALY reflects one year in full $\mathrm{HrQOL}$ ), concordance index (reflecting the accuracy of the prognosis) and the proportion correctly reclassified.

\section{Sensitivity analysis}

The clinical expert opinions, the empirical evidence and the various assumptions made in this simulation study were subject to a degree of uncertainty, which resulted in uncertainty in the estimated costs and QALYs. In a probabilistic sensitivity analysis, parameter uncertainty was assessed by running the model 10,000 times, each time using a different set of plausible input values by randomly drawing them from their parameter distributions (see Table 2) (see Supplementary Material $\S 3.4$ for details).

\section{RESULTS}

\section{Main outcomes}

The simulated sample of 20,000 virtual patients had an average age of 69 years, $45 \%$ were female, and they had an average MMSE of 27.0 and a 5-year prevalence of progression to dementia of $25 \%$ (see Table 1). In $46 \%$ the risk of progression to dementia between before and after using CSF tests was 0.10 or more (on a scale from 0 to 1 ). In this subsample, $68 \%$ of the risk changes was correct (meaning an increased risk over time and actually progressing 
to dementia, or a decreased risk over time and not actually progressing to dementia). The concordance index was 0.705 for the control strategy and 0.801 for the intervention strategy.

The intervention strategy resulted in more positive prognoses $(14 \%$ versus $10 \%$ in the control strategy), more false-negative prognoses (5\% versus $4 \%$ in the control strategy), fewer false-positive prognoses ( $16 \%$ versus $20 \%$ in the control strategy), and more follow-up visits (on average 2.04 visits per patient versus 1.80 visits in the control strategy) with corresponding impact on QALYs and costs.

The simulation estimated a 0.046 mean QALY gain and $€ 432$ mean additional costs per patient when adding the lumbar puncture to the usual-care diagnostic workup for the prognosis of progression to dementia in MCI. This resulted in an incremental cost-effectiveness ratio of $€ 9,416$. Assuming a willingness-to-pay of $€ 20,000$ per QALY, the incremental net monetary benefit was $€ 486$.

\section{Uncertainty}

These outcomes were subject to uncertainty. The incremental cost-effectiveness plane in Fig. 3 reflects how the uncertainty of most input parameters in the model (e.g., expert opinions and risk prediction coefficients) resulted in uncertainty in the costs and QALY outcomes. Of the plausible scenarios, 95\% had incremental costs of between $€-767$ and $€ 1,165$, incremental QALYs of between -0.145 and 0.314 and incremental net monetary benefit of between $€-3,829$ and $€ 6,440$.

Scenarios with a negative net monetary benefit are unwanted. These are reflected by the red-shaded area in Fig. 3; the blue dots in the left top quadrant (33\% of all plausible scenarios), indicating an HrQOL loss at higher costs; and the blue dots in the right top quadrant above the willingness-to-pay threshold of $€ 20,000$ per QALY (12\%), indicating the unwanted situation of improved QALY but at unacceptably high costs. Sixteen percent of all plausible scenarios resulted in the preferred outcome of improved QALY and cost savings, and $40 \%$ led to improved QALY outcomes at acceptable costs below the willingness-to-pay threshold (reflected by the green-shaded area in Fig. 3). Less than 1\% fell in the lower left quadrant, indicating a QALY loss at lower costs. Assuming a willingness-to-pay of $€ 20,000$ for a gain of 1 QALY, $56 \%$ of all plausible scenarios were cost-effective. In other words, there was a $56 \%$ chance that adding the lumbar puncture to

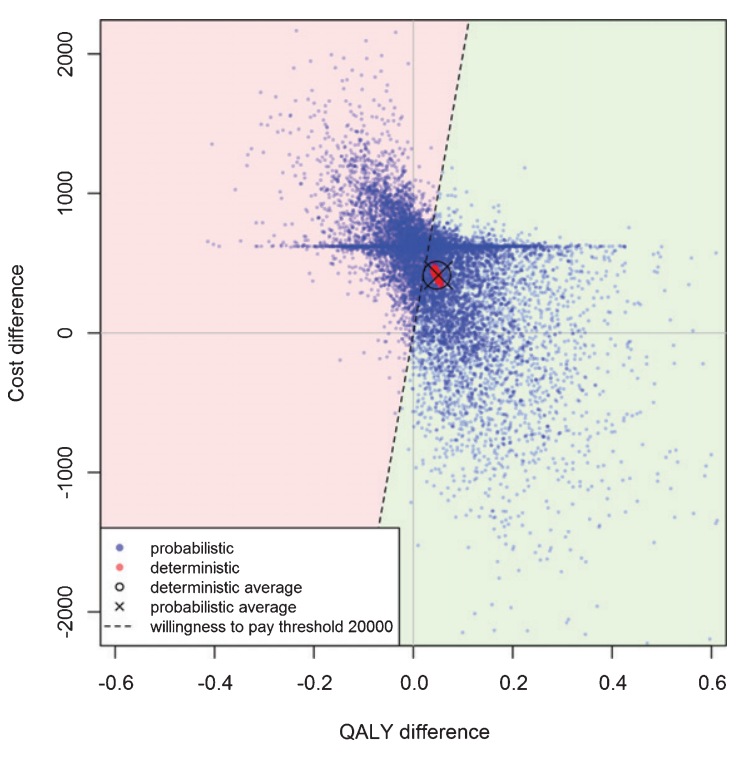

Fig. 3. Incremental cost-effectiveness plane. Each blue dots represents the average incremental costs and average incremental QALYs for 5,000 simulated patients in the control strategy and intervention strategy, using 10,000 different sets of random parameter draws from a plausible distribution, reflecting parameter uncertainty. The red dots represent 5,000 simulated patients in the deterministic mode reflecting stochastic uncertainty. The black open circle and cross represent the average incremental costs and effects of the deterministic and probabilistic results, respectively. The green shaded area to the right of the dashed line represents scenarios cost-effective at a willingness-to-pay of $€ 20,000$ per incremental QALY; the red shaded area to the left of the dashed line represents scenarios that are not cost-effective.

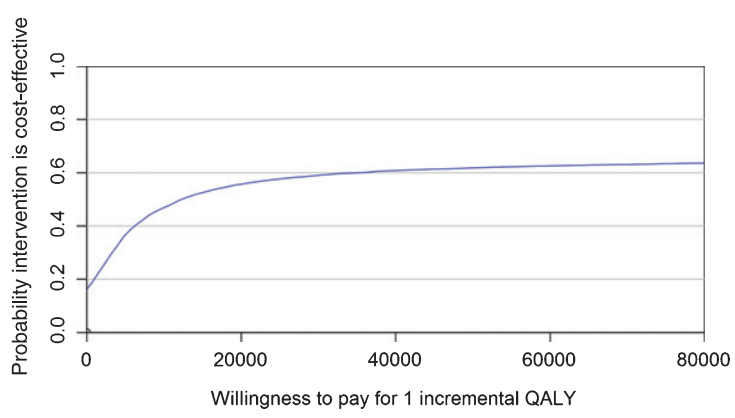

Fig. 4. Incremental cost-effectiveness acceptability curve representing the probability of CSF being cost-effective at various levels of willingness to pay for 1 QALY.

the usual-care diagnostic workup would result in cost-effective care. Assuming a willingness-to-pay of $€ 80,000$ per QALY, this was $64 \%$ (see Fig. 4). In other words, $64 \%$ of the plausible scenarios were cost-effective (implicates $36 \%$ were not).

The univariate sensitivity analysis showed the impact of various specific plausible scenarios on the cost-effectiveness of adding CSF testing. The costs of 
the lumbar puncture, the impact of stigma, the impact of reduced worrying, the impact of a false-negative prognosis, and the cut-off value at which the probability that a person will be followed up had the highest impact on the cost-effectiveness outcomes (see Supplementary Material §5.2). For example, a higher assumed impact of a false-negative prognosis by the clinical experts resulted in a lower incremental net monetary benefit, because the intervention strategy resulted in more false-negative prognoses $(5 \%$ versus $4 \%$ in the control strategy). Since the intervention strategy resulted in fewer false-positive prognoses ( $16 \%$ versus $20 \%$ in the control strategy), its relation with incremental monetary benefit was opposite for the impact of a false-positive compared to the impact of a false-negative. Similarly, since more positive prognoses occurred in the intervention group (14\% versus $10 \%$ in the control strategy), a higher stigmatizing effect resulted in a lower incremental net monetary benefit. The uncertainty about the complications of a lumbar puncture and the impact and duration of headache had almost no impact on the cost-effectiveness.

Omitting the specific uncertainty from the beta estimates of the logistic regression prediction model resulted in $74 \%$ and $91 \%$ of all plausible scenarios being cost-effective at a willingness-to-pay of $€ 20,000$ and $€ 80,000$ per QALY, respectively (see Supplementary Material $\S 5.2$ ).

\section{DISCUSSION}

Determining CSF biomarkers in addition to the usual-care diagnostic workup to establish the prognosis for progression to dementia resulted in an average potential gain of 0.046 QALYs at $€ 432$ additional costs. This corresponds to a potential cost-effectiveness ratio of $€ 9,416$ per QALY. These estimates were, however, highly uncertain, because even assuming a willingness-to-pay of $€ 80,000$ per QALY gained, the likelihood that adding CSF biomarkers is cost-effective was only $64 \%$, corresponding to a $36 \%$ likelihood that it is not.

This early technology assessment reflected the potential value of CSF testing in the pre-dementia state, in which no treatment is available, by estimating plausible impacts of reduced worrying, stigma and false-positive and false-negative prognosis. The health-economic outcomes show that on average the benefits could outweigh the harms, thus indicating the potential of CSF testing for prognostic purposes. However, the uncertainty in the results was considerable and makes it difficult to draw strong conclusions for the purpose of reimbursement by governments or health insurers. Nevertheless, our study yielded various useful insights.

The model showed the combined impact of adding CSF biomarkers to the usual-care diagnostic workup. The cost-effectiveness estimate can be seen as a set of trade-offs. For example, the investment in performing a lumbar puncture reduced the costs of following up patients. Another example is that a gain in QALYs due to reduced worrying because of a correct positive prognosis as a result of the lumbar puncture came at the cost of a loss of QALYs due to the stigmatizing effect of the positive prognosis. These set of tradeoffs indicate the importance of a holistic viewpoint and moving forward from the typical assumption that improved prognostic or diagnostic accuracy in terms of sensitivity and specificity reflects clinical utility. Despite the positive cost-effectiveness outcome of this study, the QALY gain of 0.046 was small, representing an average quality-of-life improvement of 0.009 (on a scale of 0 representing death and 1 representing full quality of life) for a duration of 5 years, as mortality did not differ between the control and intervention strategies.

\section{Comparison with other studies}

There have been other studies evaluating the incremental cost-effectiveness of using CSF biomarkers. The majority of these studies [18-22] used a hypothetical future scenario in which disease-modifying treatment is available that significantly reduces the rate of progression. Such studies have evaluated the impact of using a CSF test on decision making for treatment, and showed that this was potentially cost-effective. A study by Valcárcel-Nazco et al. [17] evaluated CSF biomarkers for decisions about off-label Donepezil treatment in MCI. They showed lower costs per correctly diagnosed patient when using CSF biomarkers $(€ 1,336)$ versus using standard clinical diagnostic criteria $(€ 3,167)$, on the assumption that this off-label treatment is both effective and reduces costs in MCI. Potential non-medical impacts such as reduced worrying, falsepositive/negative prognosis and stigmatization were not assessed, as the study disregarded HrQOL. Our study is the first to attempt to assess the value of CSF testing in actual current clinical practice in terms of HrQOL and costs. 


\section{Recommendations}

We recommend empirical research into the parameters to which the health-economic outcomes were most sensitive. These included the impact of stigma, the impact of reduced worrying and the impact of a false-negative prognosis. Uncertainty caused by the uncertain costs of performing a lumbar puncture and the uncertain costs of performing a follow-up visit could be solved by applying the fixed price from the specific hospital in which the CSF technology is to be implemented. The uncertainty in the cut-off value to decide about following up patients should be the topic of an optimization analysis, as this can generate the optimal cut-off value to ensure cost-effective application of CSF testing in practice. Furthermore, our results indicated that the evidence base on side effects due to CSF assessment is sufficiently large. Uncertainty due to the logistic regression prediction model was probably overestimated, as data from other studies have been collected in other studies but were not requested by us.

The model framework supported the concept of including potential health effects for the evaluation of a diagnostic test. Although the discrete event simulation increased the level of complexity compared to the well-established Markov model, it allowed the inclusion of various levels of uncertainty without losing detail due to categorizing them into states [24]. If health effects do indeed occur within the relatively short time period of 5 years, a trial-based economic evaluation could serve as an alternative, though involving a risk of bias if there is no option of blinding for undergoing a lumbar puncture and for interpreting the test result. Nevertheless, a model framework has the potential to identify subgroups for whom cost-effectiveness is high [29].

\section{Limitations}

The simulation model is a simplistic representation of the real-world situation. Actual current practice is more complex and heterogeneous, especially in terms of the medical decisions made with or without relying on biomarkers and between positive, negative or intermediate test outcomes, which were not taken into account in our study. Furthermore, the way a probability or risk is communicated to and received by a person most likely varies considerably. Discounting was disregarded, as insufficient resources were available to build this into the model. Discounting would likely lower the cost-effectiveness, as costs occurred at the start, while savings due to reduced followups and effects occurred later in time, although the impact is likely to be low, due to the relatively short time period. By adopting a health-care sector perspective, we omitted out-of-pocket expenses such as travel costs, informal caregiving time, and productivity losses, factors for which it is difficult to indicate whether they would have led to over- or underestimation of the cost-effectiveness. The results of this study are therefore mainly useful to estimate the potential of CSF testing for scientific purposes, rather than to advise upon clinical management in practice or policy. These limitations were of secondary relevance to the exploratory nature of this study, to show the balance regarding the non-medical impact of testing. Nevertheless, our extensive sensitivity analysis covered a wide range of plausible inputs and methodological choices made, making their impact on results transparent (see Supplementary Material $\S 6$ for details).

Expressing health effects of diagnostic information in terms of QALYs might be challenging. Scales like the ICECAP provide an index of capabilities [30], which could be more sensitive to the effects of diagnostic information, and constitute an alternative to EQ5D-based utility scores.

\section{Conclusions}

Adding CSF tests to the usual-care diagnostic workup for the prognosis of progression to dementia in persons with MCI was cost-effective when relying on expert opinion about its expected impact in current practice. This result was, however, highly uncertain and calls for empirical research into the impact of a prognosis on the aspect of reducing worrying, false-positive and false-negative prognosis, and stigmatization.

\section{ACKNOWLEDGMENTS}

We would like to thank the experts Dr. Jurgen Claassen, Dr. Edo Richard, Dr. Peter van Domburg, Dr. Albert Leentjens, and AW, FV, and JML for their responses to the expert opinion questionnaire.

This work is part of the BIOMARKAPD project within the EU Joint Programme for Neurodegenerative Diseases Research (JPND). This project is supported by the following funding organizations under the aegis of JPND - http://www.jpnd.eu: Netherlands: ZonMW- The Netherlands Organisation 
for Health Research and Development grant number 629000002; Sweden: Swedish Research Council, C0001401; Slovenia: Slovenian Research Agency and partly from the programme with grant number L3-4255-0312 - Early Detection and rational therapy of dementia. The Karolinska Institutet research group is partly funded by the Swedish Brain Power programme. The funders had no role in the study design, data collection and analysis, decision to publish, or preparation of the manuscript.

Authors' disclosures available online (http://j-alz. com/manuscript-disclosures/17-0324r1).

\section{SUPPLEMENTARY MATERIAL}

The supplementary information is available in the electronic version of this article: http://dx.doi.org/ 10.3233/JAD-170324.

\section{REFERENCES}

[1] Prince M, Guerchet M, Prina M (2015) The Epidemiology and Impact of Dementia: Current State and Future Trends, World Health Organization, Geneva.

[2] Prince M, Wimo A, Guerchet M, Ali G, WU Y, Prina M (2015) World Alzheimer Report 2015 The Global Impact of Dementia. Alzheimer's Disease International, London.

[3] Hort J, O'Brien JT, Gainotti G, Pirttila T, Popescu BO, Rektorova I, Sorbi S, Scheltens P, EFNS Scientist Panel on Dementia (2010) EFNS guidelines for the diagnosis and management of Alzheimer's disease. Eur J Neurol 17, 12361248.

[4] Jack CR, Albert MS, Knopman DS, McKhann GM, Sperling RA, Carrillo MC, Thies B, Phelps CH (2011) Introduction to the recommendations from the National Institute on Aging-Alzheimer's Association workgroups on diagnostic guidelines for Alzheimer's disease. Alzheimers Dement 7, 257-262.

[5] Dubois B, Feldman HH, Jacova C, Dekosky ST, BarbergerGateau P, Cummings J, Delacourte A, Galasko D, Gauthier S, Jicha G, Meguro K, O'brien J, Pasquier F, Robert P, Rossor M, Salloway S, Stern Y, Visser PJ, Scheltens P (2007) Research criteria for the diagnosis of Alzheimer's disease: Revising the NINCDS-ADRDA criteria. Lancet Neurol 6, 734-746.

[6] Dubois B, Feldman HH, Jacova C, Hampel H, Molinuevo JL, Blennow K, DeKosky ST, Gauthier S, Selkoe D, Bateman R, Cappa S, Crutch S, Engelborghs S, Frisoni GB, Fox NC, Galasko D, Habert M-O, Jicha GA, Nordberg A, Pasquier F, Rabinovici G, Robert P, Rowe C, Salloway S, Sarazin M, Epelbaum S, de Souza LC, Vellas B, Visser PJ, Schneider L, Stern Y, Scheltens P, Cummings JL (2014) Advancing research diagnostic criteria for Alzheimer's disease: The IWG-2 criteria. Lancet Neurol 13, 614-629.

[7] Albert MS, DeKosky ST, Dickson D, Dubois B, Feldman HH, Fox NC, Gamst A, Holtzman DM, Jagust WJ, Petersen RC, Snyder PJ, Carrillo MC, Thies B, Phelps CH (2011) The diagnosis of mild cognitive impairment due to Alzheimer's disease: Recommendations from the National Institute on
Aging-Alzheimer's Association workgroups on diagnostic guidelines for Alzheimer's disease. Alzheimers Dement 7, 270-279.

[8] Vos SJB, Verhey F, Frölich L, Kornhuber J, Wiltfang J, Maier W, Peters O, Rüther E, Nobili F, Morbelli S, Frisoni GB, Drzezga A, Didic M, van Berckel BNM, Simmons A, Soininen H, Kloszewska I, Mecocci P, Tsolaki M, Vellas B, Lovestone S, Muscio C, Herukka S-K, Salmon E, Bastin C, Wallin A, Nordlund A, de Mendonça A, Silva D, Santana I, Lemos R, Engelborghs S, Van der Mussele S, Alzheimer's Disease Neuroimaging Initiative, Freund-Levi Y, Wallin ÅK, Hampel H, van der Flier W, Scheltens P, Visser PJ (2015) Prevalence and prognosis of Alzheimer's disease at the mild cognitive impairment stage. Brain 138, 1327-1338.

[9] Ferrante di Ruffano L, Hyde CJ, McCaffery KJ, Bossuyt PMM, Deeks JJ (2012) Assessing the value of diagnostic tests: A framework for designing and evaluating trials. $B M J$ 344, e686.

[10] Lijmer JG, Leeflang M, Bossuyt PMM (2009) Proposals for a phased evaluation of medical tests. Med Decis Mak 29, E13-E21.

[11] Meijs AP, Claassen JAHR, Rikkert MGMO, Schalk BWM, Meulenbroek O, Kessels RPC, Melis RJF (2015) How does additional diagnostic testing influence the initial diagnosis in patients with cognitive complaints in a memory clinic setting? Age Ageing 44, 72-77.

[12] Handels RLH, Joore MA, Vos SJB, Aalten P, Ramakers IHGB, Rikkert MO, Scheltens P, Jansen WJ, Visser P-J, van Berckel BMN, van Domburg P, Smid M, Hoff E, Hoogmoed J, Bouwman F, Claassen J, Leentjens AFG, Wolfs CAG, Severens JL, Verhey FRJ (2016) Added prognostic value of cerebrospinal fluid biomarkers in predicting decline in memory clinic patients in a prospective cohort. J Alzheimers Dis 52, 875-885.

[13] Duits FH, Prins ND, Lemstra AW, Pijnenburg YAL, Bouwman FH, Teunissen CE, Scheltens P, van der Flier WM (2015) Diagnostic impact of CSF biomarkers for Alzheimer's disease in a tertiary memory clinic. Alzheimers Dement 11, 523-532.

[14] Dubois B, Padovani A, Scheltens P, Rossi A, Dell'Agnello G (2015) Timely diagnosis for Alzheimer's disease: A literature review on benefits and challenges. J Alzheimers Dis 49, 617-631.

[15] Robinson L, Gemski A, Abley C, Bond J, Keady J, Campbell S, Samsi K, Manthorpe J (2011) The transition to dementiaindividual and family experiences of receiving a diagnosis: A review. Int Psychogeriatr 23, 1026-1043.

[16] Paulsen JS, Nance M, Kim J-I, Carlozzi NE, Panegyres PK, Erwin C, Goh A, McCusker E, Williams JK (2013) A review of quality of life after predictive testing for and earlier identification of neurodegenerative diseases. Prog Neurobiol 110, 2-28.

[17] Valcárcel-Nazco C, Perestelo-Pérez L, Molinuevo JL, Mar J, Castilla I, Serrano-Aguilar P (2014) Cost-effectiveness of the use of biomarkers in cerebrospinal fluid for Alzheimer's disease. J Alzheimers Dis 42, 777-788.

[18] Handels RLH, Joore MA, Tran-Duy A, Wimo A, Wolfs CAG, Verhey FRJ, Severens JL (2015) Early costutility analysis of general and cerebrospinal fluid-specific Alzheimer's disease biomarkers for hypothetical diseasemodifying treatment decision in mild cognitive impairment. Alzheimers Dement 11, 896-905.

[19] Sköldunger A, Johnell K, Winblad B, Wimo A (2013) Mortality and treatment costs have a great impact on 
the cost-effectiveness of disease modifying drugs in Alzheimer's disease. Curr Alzheimer Res 10, 207-216.

[20] Biasutti M, Dufour N, Ferroud C, Dab W, Temime L (2012) Cost-effectiveness of magnetic resonance imaging with a new contrast agent for the early diagnosis of Alzheimer's disease. PLoS One 7, e35559.

[21] Guo S, Getsios D, Hernandez L, Cho K, Lawler E, Altincatal A, Lanes S, Blankenburg M (2012) Florbetaben PET in the early diagnosis of Alzheimer's disease: A discrete event simulation to explore its potential value and key data gaps. Int J Alzheimers Dis 2012, 548157.

[22] Barnett JH, Lewis L, Blackwell AD, Taylor M (2014) Early intervention in Alzheimer's disease: A health economic study of the effects of diagnostic timing. BMC Neurol 14, 101.

[23] IJzerman MJ, Steuten LMG (2011) Early assessment of medical technologies to inform product development and market access. Appl Health Econ Health Policy 9, 331-347.

[24] Handels R, Vos S, Kramberger M, Jelic V, Blennow K, van Buchem M, van der Flier W, Freund-Levi Y, Hampel H, Olde Rikkert M, Oleksik A, Pirtosek Z, Scheltens P, Soininen H, Teunissen C, Tsolaki M, Wallin A, Winblad B, Verhey F, Visser P (2017) Predicting progression to dementia in persons with mild cognitive impairment using cerebrospinal fluid markers. Alzheimers Dement 13, 903-912.

[25] Duits FH, Martinez-Lage P, Paquet C, Engelborghs S, Lleó A, Hausner L, Molinuevo JL, Stomrud E, Farotti L, Ramakers IHGB, Tsolaki M, Skarsgård C, Åstrand R, Wallin A,
Vyhnalek M, Holmber-Clausen M, Forlenza O V., Ghezzi L, Ingelsson M, Hoff EI, Roks G, de Mendonça A, Papma JM, Izagirre A, Taga M, Struyfs H, Alcolea DA, Frölich L, Balasa M, Minthon L, Twisk JWR, Persson S, Zetterberg $\mathrm{H}$, van der Flier WM, Teunissen CE, Scheltens P, Blennow K (2016) Performance and complications of lumbar puncture in memory clinics: Results of the multicenter lumbar puncture feasibility study. Alzheimers Dement 12, 154-163.

[26] Wimo A, Religa D, Spångberg K, Edlund A-K, Winblad B, Eriksdotter M (2013) Costs of diagnosing dementia: Results from SveDem, the Swedish Dementia Registry. Int J Geriatr Psychiatry 28, 1039-1044.

[27] Wimo A, Winblad B (2003) Pharmacoeconomics of mild cognitive impairment. Acta Neurol Scand Suppl 179, 94-99.

[28] Zwaap J, Knies S, van der Meijden C, Staal P, van der Heiden L (2015) Kosteneffectiviteit in de praktijk, The Hague.

[29] van Giessen A, Moons KGM, de Wit GA, Verschuren WMM, Boer JMA, Koffijberg H (2015) Tailoring the implementation of new biomarkers based on their added predictive value in subgroups of individuals. PLoS One 10, e0114020.

[30] Coast J, Flynn TN, Natarajan L, Sproston K, Lewis J, Louviere JJ, Peters TJ (2008) Valuing the ICECAP capability index for older people. Soc Sci Med 67, 874-882. 